\title{
La domesticación de éros y poesía en las Leyes: la síntesis platónica de vida y poesía
}

\author{
Ma Elena Macua Martínez $^{1}$
}

Recibido: 10 de febrero de 2017 / Aceptado: 30 de enero de 2018

Resumen. Este trabajo constituye la última fase de un estudio que pretende destacar la profundidad de la huella de la poesía en el pensamiento de Platón, poniendo de manifiesto que la evolución de su tratamiento en las Leyes (con respecto a la República), se corresponde con otra paralela, y del mismo signo, en el éros; y planteando una interpretación del último modelo platónico de ciudad como logro del anhelo frustrado de los poetas de la generación precedente: la síntesis de vida y poesía. A ella llega Platón creando un nuevo equilibrio entre las fuerzas en tensión que espolean el deseo humano, y revirtiendo el proceso de desacralización del lenguaje poético consumado por Gorgias, con lo que consigue cerrar por fin la fractura entre poesía trascendente y poesía pragmática, y hacer confluir en una idéntica naturaleza, divina e inmutable, el lógos de la poesía y el de la ley.

Palabras clave: Platón. Poesía. Éros.

[en] The domesticity of éros and poetry in the Laws: Platonic synthesis of life and poetry

\begin{abstract}
This paper is the last part of a study which outlines the depth of poetry in Plato's thought, suggesting that Plato's evolution concerning the Laws (regarding the Republic), run parallel to his views on éros. From this it follows an interpretation of Plato's last model of the city as the achievement of the frustrated longing of the poets of the former generation: a synthesis of life and poetry. Plato reaches his aim by creating a new equilibrium between the forces in tension that spur on by human desire, and by reverting to the process of demystification of the poetic language already carried out by Gorgias, in this way, at last, Platon succeeds in closing the fracture between transcendental and pragmatic poetry and merges in one and only single nature, divine and immutable, the lógos of poetry and the lógos of the law.
\end{abstract}

Keywords: Plato. Poetry. Éros.

Cómo citar: Macua Martínez, M. E. (2018) La domesticación de éros y poesía en las Leyes: la síntesis platónica de vida y poesía, en Cuadernos de Filología Clásica. Estudios griegos e indoeuropeos 28, 115-128. 
Este trabajo constituye la última fase de un estudio que pretende demostrar dos hipótesis: la primera, que las distintas concepciones del éros y de la poesía en Platón son interdependientes y evolucionan indefectiblemente unidas hasta su último diálogo, las Leyes; la segunda, que sus dos grandes modelos de Estado (los de República y Leyes) se articulan en tan estrecha conexión con aquéllas que pueden interpretarse como intentos sucesivos de materialización, posible a más largo o corto plazo, de los espacios que construyeron los poetas para integrar la dualidad de las aspiraciones humanas (la necesidad de sobrevivir aquí y ahora, y el anhelo de elevarse); constructos de palabras que, para Platón, no pueden más que simular una vida que se identifica con la acción (érga).

Nuestra argumentación parte de un análisis previo ${ }^{2}$ de la reflexión platónica sobre la poesía desde una perspectiva distinta de las habituales: la de su continuidad y profunda dependencia con respecto a la teoría poética que inmediatamente la precede y que ha sido magistralmente descrita por G. B. Walsh (1984). Este estudioso considera la crisis del modelo poético tradicional, que practican por última vez Píndaro y Esquilo, como resultado de la ruptura del equilibrio entre los dos imperativos básicos de la poesía (el de ofrecer evasión y placer y, al mismo tiempo, conocimiento), con los cuales aquélla pretende colmar las necesidades en conflicto de sus receptores: las inmediatas y pragmáticas, por una parte, y las de trascendencia, por otra. La extraordinaria complejidad intelectual y política de la segunda mitad del siglo $\mathrm{V}$ ateniense parece tornar incompatibles ambos objetivos, y abocar a los poetas a una elección excluyente; pero la nueva teoría gorgiana del lógos como téchne, y su desacralización del lenguaje poético, inclinan definitivamente la balanza en favor de una poesía "técnica", pragmática, desmitificada y desmitificadora.

De la pérdida irreparable que implicaba esta escisión tuvieron conciencia lúcida algunos poetas del momento, como Aristófanes o Eurípides, en cuyas obras queda patente el anhelo de una nueva síntesis poética que, sin embargo, no hallaron. Y es precisamente en esta misma búsqueda, y en su fracaso, donde ubicamos la teoría poética platónica, que entendemos como un proceso ininterrumpido de reelaboración conceptual en pos de un objetivo que Platón alcanza por fin en las Leyes, donde consigue cerrar la grieta abierta por Gorgias mediante la asimilación del lenguaje poético por el lógos de la ley, y del papel del poeta por parte del legislador.

Esta perspectiva no sólo permite apreciar mejor la coherencia, interna e histórica, del pensamiento platónico sobre la poesía, sino que invita, además, a reexaminar la profundidad de su huella en Platón, más allá de lo explícito. En efecto, Walsh (1984: pp. 37-61 y 107-126) sostiene que Píndaro y Eurípides concibieron ya su poesía como una especie de alquimia del éros, como creación de un espacio intermedio donde integrar la dualidad del deseo humano y hacer realidad la armonía individual y colectiva. Esta interpretación induce a pensar que tal vez la teoría platónica del éros y los proyectos políticos de República y Leyes, fueron también concebidos como réplica y superación de las propuestas fallidas de esos poetas.

Ya en los años sesenta, Grassi proponía una clave semejante de lectura de Platón: lejos de justificar su visión ontológica, no estética, del arte en general, como fruto de un pasado superado, Grassi (1962: pp. 108s.) señalaba las afinidades entre la concepción platónica de la poesía como medio de alcanzar la perfección, como compromiso que requiere la activación de la existencia humana completa y cuya forma suprema

Macua (2014: pp. 123-144). 
es el drama de la realización del estado; y las de Rimbaud o Baudelarie, que quisieron arrebatar lo poético al ámbito literario, atribuyéndole la capacidad de transformar la realidad y de trascenderla en su inmediatez (1962: pp. 18-21). Una clave de lectura de Platón que sigue dando también en nuestros días frutos extraordinarios ${ }^{3}$.

Para Platón, mucho antes que para los románticos ${ }^{4}$, la teoría de la poesía fue una teoría de la vida; y de ello da prueba la pareja evolución que las concepciones del éros y de la poesía experimentan en sus diálogos. Este vínculo forma parte, además, del legado poético del siglo $\mathrm{V}$, por el que Platón se sintió siempre interpelado, y al que replicó con sus propias reelaboraciones del éros y de los terrenos poéticos de alianza entre realidad y deseo.

Sostener que las teorías política, erótica y poética platónicas experimentan una evolución notable, y que lo hacen en perfecta imbricación, en pos de un objetivo que permanece constante y que Platón compartió con los poetas de la generación precedente, no sólo no cuestiona su coherencia, sino más bien todo lo contrario ${ }^{5}$. Por otra parte, creemos haber probado la validez de esta hipótesis en Fedro, Banquete y República ${ }^{6}$, que representan, desde nuestro punto de vista, fases sucesivas del proceso ascendente que jalona esta búsqueda. Los tres diálogos afirman la potencia creativa del éros para intervenir en la realidad, y rechazan las poco satisfactorias propuestas de los poetas, de Eurípides en particular, para conciliar la realidad y el deseo. El Fedro emprende la demolición del precario espacio metafísico construido en su Hipólito sobre la convicción de la impotencia del hombre para acceder a lo divino, y la satisfacción necesariamente efímera de este anhelo a través del culto y de la poesía, que "destilan gota a gota... el brillo de ámbar de las lágrimas" (Hipp. 738-741). Quizá por ello sostiene Platón que "jamás hubo poeta de los de aquí" que alcanzara ese "lugar supraceleste" (247c) donde se conoce la verdadera trascendencia: la inmortalidad del alma y el poder ascensional de un éros que, partiendo de la pasión terrena, conduce a la sabiduría, y comparte con la poesía genuina su fuente y su meta: la divinidad.

Este nexo entre poesía y filosofía se quiebra, sin embargo, en el Banquete, diálogo que perfila la distinción entre el "saber erótico" de los poetas y el del propio Platón, a través de la oposición, por primera vez explícita en la tradición griega, entre éros "específico" y éros "genérico", encarnados en Alcibíades y Sócrates respectivamente. Partiendo de una interpretación literal de la intervención de Alcibíades como drama satírico, pensamos que el diálogo está articulado como una trilogía trágica, como

3 Entre ellos, el ensayo de Andrés Ruiz sobre la poesía de Virgilio y Baudelaire, que parte de una visión de Platón como "hombre dolientemente moderno..., dolientemente consciente... de que el pensamiento crítico destruye lo que nombra, o de que separa, diríamos, lo unido en una anterioridad a él inasequible..., mordido de continuo por el deseo y atacado por la melancolía de la siempre irrecuperable vida tácita... la vida de la inocencia o la unidad que se perdió y que no pudo ser al mismo tiempo vivida y pensada. ... Es esta imposibilidad de vivir lo que se piensa y de pensar lo que se vive, la que mueve a la honestidad de Platón a tomar conciencia de la mentira en que consiste la representación imaginaria con la que toda restauración pretende la restitución de lo perdido, es decir, la recuperación (reflexiva, productiva, actual) de aquello que, cuando estuvo vivo en la realidad, lo estuvo sin participación de arte ni de reflexión ni de voluntad..." (2017: p. 27).

4 Bloom (1999: p. 34).

5 Boehringer (2007: p. 67), por ejemplo, justifica con motivos pragmáticos o programáticos el cambio que se produce en las Leyes, con respecto a los diálogos platónicos precedentes, en el tratamiento de la homosexualidad. Pero esta justificación no niega lo evidente: el cambio en sí, que no desaparece por más que se modifiquen el contexto o su denominación.

6 Macua (2016: pp. 145-167).

7 Ludwig (2002: pp. 130-151). 
gradación ascendente en la búsqueda de un éros superior, cuyo sentido y alcance se desplegarán definitivamente en la República: despojar al hombre de su falso individualismo ofreciéndole el verdadero, hacerlo consciente de su posición y cometido en el $\operatorname{cosmos}^{8}$, y permitirle participar en la creación de un terreno intermedio real y compartido, el único que, precisamente por ser tal, ofrece plenitud auténtica9 9

De hecho, la República gira en torno a dos oposiciones fundamentales (áno/káto, gobernante/poeta), y culmina con una crítica devastadora de la Helena de Eurípides, obra que Platón evita mencionar, pero cuyo asedio emprende a través de su particular interpretación de la palinodia de Estesícoro, la misma que inspiraba la rectificación piadosa de Sócrates sobre el amor en el Fedro. En su tragedia, Eurípides sugiere que éros y poesía ofrecen al hombre una vía alternativa de construcción de sentido, y le permiten operar activamente sobre la única realidad que nos es accesible: la psicológica. Para Platón, sin embargo, el de Eurípides es un éros infantil y autocomplaciente, incapaz de crear el espacio de plenitud anhelado, porque, en su ensimismamiento, colapsa tanto el camino hacia arriba como el camino hacia abajo, que son, como decía Heráclito (fr. A 33), uno y el mismo; sí acepta, en cambio, el planteamiento euripideo de su afinidad con la poesía, con la que comparte un territorio de eídola y phantásmata poblado por tiranos, al que él opone el de los érga fundados en la sabiduría, que atrapan y dan cuerpo al deseo de un mundo a la medida genuina del hombre.

Lo que intentaremos demostrar aquí, a través de un análisis de la ciudad de las Leyes desde idéntica perspectiva, es que Platón persistió en esta búsqueda hasta el final de sus días; y que de ella es fruto la "corrección a la baja" del ideal de la $R e$ pública, al que nunca renunció, pero de cuya incompatibilidad con la realidad histórica le hicieron tomar conciencia, tanto la acogida de esta obra en Atenas, como las amargas experiencias de sus últimos años de vida ${ }^{10}$. Es obvio, en consecuencia, que no compartimos la tesis de quienes afirman que las diferencias fundamentales entre República y Leyes obedecen a la distinta naturaleza de los proyectos que abordan (teórico una, netamente político la otra). Menos aún si la argumentación se basa, como hace Mouze (2005: pp. 9-10, 142, 147, 186), en el tipo de tratamiento que recibe la poesía en uno y otro diálogo. La poesía es, en efecto, la clave de lectura de las Leyes, tal como ella afirma, pero también, y en no menor medida, de la República, como creemos haber demostrado ya ${ }^{11}$ : Platón configura estos dos proyectos, políticos ambos, como réplica y superación de los de los poetas, y es precisamente la República, y no las Leyes, la que concluye con la defensa de la que es, para su autor, la aportación sustancial de su propuesta frente a la de Eurípides: el realismo. La pólis de República no se asienta en un espacio fugaz y privado, fantaseado por un éros autocomplaciente, como el de su Helena, sino en un espacio real, maduro y compartido, semejante al éros que lo sostiene ${ }^{12}$. Y bajo este mismo imperativo de

\footnotetext{
Colli (2008: p. 121).

Todorov (2007: pp. 31-40).

10 Colli (2008: pp. 129-132). Aunque para otros estudiosos de Platón que también defienden su confianza en la posibilidad de realizar el proyecto de República, carece de fundamento hablar de las Leyes en términos de "corrección", y más aún de justificarla con tales argumentos, puesto que Platón siempre habría sido consciente de la enorme dificultad de llevar a cabo el programa de la República (Bruchmüller 2009: pp. 175-195). Desde nuestra perspectiva, sin embargo, la clave de la cuestión está en el realismo de ambos proyectos, por las consecuencias que de ello derivan, como a continuación trataremos de exponer.

11 Macua (2016: pp. 20s.).

12 Macua (2016: pp. 159-165).
} 
realismo, comprensiblemente recurrente en las Leyes, ajustará, sin renunciar a ellos, los principios de la República ${ }^{13}$.

En efecto, el hueco que media entre la República y las Leyes refleja el abismo que se ha venido abriendo en el pensamiento platónico entre lo ideal y lo real desde su composición del Teeteto; hueco sobre el que tiende un puente el Político, donde

los dos puntos de vista que bullían en la mente del autor salen a la luz de modo palmario, solapándose y contradiciéndose alternativamente: o bien se sitúa en primer plano al verdadero político que, en posesión de la filosofía y superior a sus súbditos y a las leyes, reina otorgando la felicidad al Estado, o bien el autor parece desesperar de la existencia de este hombre superior, y entonces sobresale la ley como única solución a los desórdenes y los males de la comunidad ${ }^{14}$.

El eco de estas contradicciones resuena todavía en las Leyes, cuando el legislador pide como don de la fortuna y complemento de su téchne, "la ciudad sometida a un tirano... joven, de buena memoria, dócil, valeroso y magnífico por naturaleza"

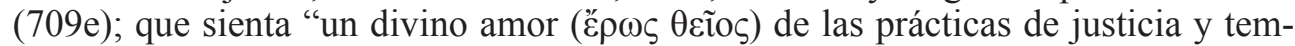
planza" (711d), y que marche "él mismo el primero por el camino... de virtud... dictándolo todo con su conducta..." (711b). Al tiempo que culpa a la tiranía de acabar

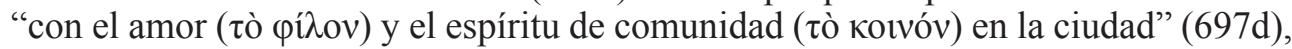
y convoca, una vez más, al fantasma de Alcibíades en el individuo que

exaltado por su arrogancia o ufano por sus riquezas, sus honores o acaso por la hermosura de su cuerpo unida a su juventud e insensatez, inflama su alma de insolencia (v̋ $\beta \varepsilon \omega \varsigma)$... es abandonado en soledad por la divinidad, y... salta locamente perturbándolo todo. Y hay muchos que lo tienen por hombre de valía; pero sin que pase mucho tiempo... se derrumba a sí mismo y derrumba su casa y su ciudad (716a-b).

En este momento, Platón ha perdido la confianza en la educación en la dialéctica, y en las posibilidades del hombre de superar su condición natural y acceder a lo divino; y no ve otra alternativa que encauzar su conducta con normas impuestas desde el exterior. De ahí su interés por la legalidad, y su propuesta de un programa donde la moral ha cedido su lugar al derecho; de ahí también el estatismo de las Leyes, la desaparición del tránsito entre el arriba y el abajo que impulsaba la República: lo divino y lo humano han pasado a ser términos incomunicables entre sí. Como en el Hipólito de Eurípides ${ }^{15}$.

Con todo, jamás renunció Platón al contacto con el mundo ideal, aunque el vínculo que establece ahora entre éste y lo real es la religión, la espina dorsal en el Estado de las Leyes tal como la sabiduría lo había sido en el de la República; una religión que no es ya, sin embargo, éros, aspiración íntima del individuo a la divinidad, sino

\footnotetext{
13 Una argumentación ontológica de la confianza de Platón en la posibilidad de realizar el Estado de República puede encontrarse en Bruchmüller (2009: pp. 181-189 especialmente), donde rebate la interpretación de Laks de la ciudad de las Leyes como la solución más elevada para su modelo de Estado ideal. Como Bruchmüller (2009: pp. 190-193), creemos que Platón la consideraba, sobre todo, más fácil de realizar: por tanto, mejor exclusivamente en ese sentido.

14 Colli (2008: p. 142).

15 Macua (2016: pp. 148-151).
} 
"contacto puramente exterior con el dios, que se efectúa a través de las manifestaciones del culto. La divinidad, a su vez, demuestra su interés por los hombres dándoles leyes... como principios que establecen el límite de la razón al desordenado movimiento del mundo empírico" $"$.

De este tipo de relación entre la divinidad y el hombre surge el presupuesto básico de la obra, que se formula en términos semejantes a los del Fedro, el Banquete y la República, y vincula injusticia y ateísmo, alimentados ambos por "los sabios actuales", i $\delta 1 \omega \tau \tilde{\omega} \nu \tau \varepsilon \kappa \alpha i ̀ ~ \pi o i \eta \tau \tilde{\omega} v$, quienes indistintamente afirman

que la justicia es aquello que cada cual llega a imponer por la fuerza; de ahí vienen a los jóvenes esas impiedades, con el pensamiento de que no existen los dioses tales como la ley prescribe concebirlos; de ahí también las sediciones, el arrastrar

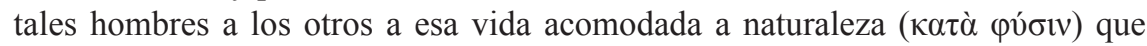
consiste en vivir dominando a los demás en vez de servir al prójimo conforme a la

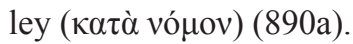

Por otra parte, la irrenunciable mirada de Platón "hacia arriba" sostiene la fidelidad de algunos principios fundamentales de las Leyes al espíritu de la República: así, que "el dios, ciertamente, ha de ser nuestra medida de todas las cosas; mucho mejor que el hombre, como por ahí suelen decir" (716c); que hemos de parecernos a la divinidad "hasta donde alcancen nuestras fuerzas" (716c); o que el orden de las leyes debe examinarse "sin tener como la multitud como lo más honroso para los hombres el salvarse y existir, sino el hacerse mejores en la medida de lo posible y continuar siéndolo mientras existan" (707d) ${ }^{17}$.

Respecto a este último planteamiento, insiste, además, el autor:

No hay ley ni ordenación alguna superior al conocimiento, ni es lícito que la inteligencia (voṽv) sea súbdita o esclava de nadie, sino que ha de ser señora de todo si es verdadera inteligencia y realmente libre por naturaleza. Pero lo que ocurre es que tal cosa no se da absolutamente en ninguna parte sino en pequeña proporción; y por ello se ha de escoger el otro término, la ordenación y la ley... (875c-d)

Por ello, también, se recuerda a sí mismo Platón: "Estamos hablando con hombres, no con dioses. Mas sucede que lo humano por naturaleza son los placeres, los dolores y los deseos" (732e). De modo que el legislador, como cualquier mortal, ha de poner coto a sus expectativas, de entre las cuales

\footnotetext{
Colli (2008: p. 167).

17 Esta es, según Han (2014: p. 35), una de las diferencias más notables entre el pensamiento griego y el actual, que desnuda la vida "de toda trascendencia de valores" y la reduce "a la inmanencia de la función vital" (2016: p. 197); lo que genera la sacralización de la salud, y un afán insaciable por acumular riquezas como modo de escamotearse de la muerte (2016: p. 37). Sin embargo, la semejanza entre dichas ideas y algunas de las que aparecen recurrentemente en Leyes y República, parecen sugerir que lo que Platón percibía en la sociedad de su tiempo no era tan distinto de lo que percibe Han en la del nuestro: de ahí su insistencia en la necesidad de no considerar "el vivir como bien absoluto" ( $L g .727 \mathrm{~d})$, o en recordar que el hombre sensato "en lo que toca al uso y sustento de su cuerpo, no sólo no se volverá al placer fiero e irracional... sino que ni siquiera mirará su salud... si estas cosas no le sirven para la sanidad de su mente..." (R. 598e). De ahí también su consideración del ansia de acumular bienes como fuente de la mayor parte de los males para el individuo y la comunidad, que le lleva a abolir la propiedad privada en la República, y a decretar en las Leyes que la diferencia máxima entre el más rico y el más pobre no sea nunca superior al cuádruple del patrimonio básico garantizado a todos (744e).
} 
hay unas que es factible que sucedan, y otras que no; pues bien, el organizador debe querer las que son posibles, y las que no lo son, ni las querrá con vano deseo

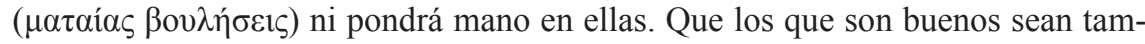
bién felices es cosa que debe suceder casi inevitablemente... pero, en cambio, que sean buenos los muy ricos es imposible... (742e)

El margen que concede ahora Platón a la capacidad humana para intervenir en la realidad se ha vuelto extraordinariamente estrecho, entre otras razones, porque el mundo de las Leyes aparece habitado por un alma malvada, una oscura potencia insuperable que "ensucia y corrompe" "las muchas cosas hermosas que hay en la vida de los hombres" (937d), y hace a éstos incapaces de administrar sus asuntos "sin henchirse de insolencia e injusticia" (713c). En otro tiempo, la divinidad les concedió el don de unos gobernantes "de un linaje más divino y mejor, los daímones" (713d); pero su intervención en el presente se ha vuelto distante, y, aunque organiza el equilibrio de fuerzas para que venza siempre el bien, en cuanto a la generación de una u otra índole, de eso nos ha dejado la responsabilidad a las voluntades de cada uno de nosotros; pues según la forma en que cada cual desee y según como sea uno

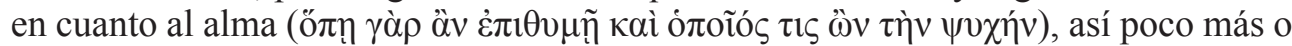
menos es como en cada caso nos hacemos todos nosotros por regla general (904b-c).

A diferencia de lo que ocurre con el tránsito entre áno y káto, sigue intensamente activo en las Leyes el otro eje sobre el que giraba la República: el de la oposición entre poeta y gobernante; aunque vira hacia una afinidad que culmina, finalmente, en síntesis. El término que, en mi opinión, define mejor el tratamiento de la poesía en esta obra es el de "domesticación", porque entraña un proceso de simplificación de su complejidad y ambivalencia que, junto con los riesgos, barre su enorme potencial creativo. En otro trabajo nos ocupamos de describir con detalle este viraje ${ }^{18}$, de manera que aquí nos limitaremos a recordar que Platón acepta ahora sin discusión el papel pedagógico de la poesía (de hecho, la paideía "aparece primeramente por obra de Apolo y de las Musas", 654b), a la que somete a una drástica reforma que la convierte en manifestación cultual; lo que implica, de acuerdo con el nuevo tipo de relación que liga lo divino y lo humano, "que los cantos se nos queden convertidos en leyes (vónovs)" (799e). Más allá de las ventajas pedagógicas y políticas de la ortodoxia poética, lo que garantiza esta medida es la perennidad del sistema, porque evita los cambios, "la cosa más peligrosa que podemos imaginar..." (797d), especialmente cuando afectan a los juegos infantiles:

... es inevitable que los niños que innovan en sus juegos lleguen a ser hombres distintos de los que antes fueron niños también, y que, una vez sean distintos, buscarán una vida igualmente distinta, y, al buscarla, desearán otras diversas leyes y maneras de conducirse... (798c).

No hay que olvidar que, en este contexto, los "juegos" a los que se refiere Platón

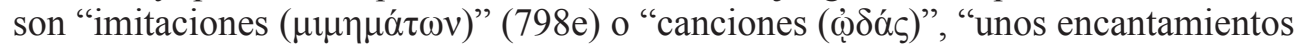
( $\dot{\varepsilon} \pi \omega \delta \alpha i)$ de las almas enderezados con toda seriedad a producir esa armonía que decimos" (659e), y que consiste en que "el alma del niño no se acostumbre a gozar o apesadumbrarse en contra de la ley" (659d). Ésta es la esencia de la virtud en las

18 Macua (2014: pp. 138-142). 
Leyes: el acuerdo entre sensibilidad y racionalidad (689a-b) que surge cuando la razón coordina y establece límites a los desordenados impulsos afectivos ${ }^{19}$; y cuyo motor es aidós, ese "nobilísimo temor divino" (671d) "a parecer malos al hacer o decir algo que no está bien" (646e-647a), que se opone, como lo hacía el thymós en la República, "a los dolores y a los otros miedos, y se opone también a los más y mayores placeres" (647a).

El aidós se expresa, naturalmente, como "miedo y obediencia a las leyes". Y de la vinculación de su suerte con la naturaleza de las prácticas poéticas da testimonio el pasado de Atenas, que se salvó en las Guerras Médicas porque el pueblo era "por su voluntad en cierto modo" esclavo de las leyes (700a), entre las que destacaba, precisamente, "la establecida entonces acerca de la música", cuyas especies no estaba permitido mezclar $(700 \mathrm{a}-\mathrm{c})$. Hasta que llegó esa raza de poetas "naturalmente dotados para la poesía" pero "ignorantes de la justicia y normas de la Musa" (700d),

diciendo que en esta no cabía rectitud de ninguna clase, y que el mejor juicio estaba en el placer del que se gozaba con ella, fuera este mejor o peor. Haciendo esta clase de composiciones y poniéndoles letra del mismo estilo, inspiraron a la multitud la transgresión de las leyes relativas a la música y la osadía de creerse capaces de juzgar... a partir de ella empezó para nosotros la opinión de que todo el mundo lo sabía todo y estaba sobre la ley, con lo cual vino la libertad. Quedaron sin miedo como gente entendida, y esta falta de temor engendró la desvergüenza $(\dot{\alpha} v \alpha 1 \sigma \chi v v \tau i ́ \alpha v) \ldots(700 \mathrm{e}-701 \mathrm{a})$.

Por ello, la preocupación fundamental de Platón en las Leyes es dar con la clave del conflicto entre poesía y ley, que ubica certeramente en la diversa perspectiva desde la que se asoman a la realidad ética: el poeta la refleja en sus contradicciones, que no quiere (ni puede, según Platón) resolver; "al legislador, en cambio, no le está permitido hacer esto en la ley, el presentar dos opiniones sobre una misma cosa, antes bien, ha de mostrar sólo una sobre cada una de ellas" $(719 \mathrm{~d})^{20}$.

La confluencia entre ambas se realiza sobre la imposición de la perspectiva de la ley, y se construye en un doble movimiento: el primero encauza la poesía dentro de una rigurosa ortodoxia de fondo y forma que la encorseta en un sistema denotativo y referencial y la aproxima a la ley, tornando su naturaleza, de sagrada, en cultual; el segundo opera en dirección inversa, y podría definirse como fagocitación del poeta por parte del legislador, que se apropia de sus recursos de "encantamiento" (así, por ejemplo, cada ley tendrá su prooimion para captar la disposición favorable de sus destinatarios, 723a-b), y de su papel en la escuela (811c-812a), donde el aprendizaje de la poesía dará paso al del tipo de discurso argumentado y dialógico que el Ate-

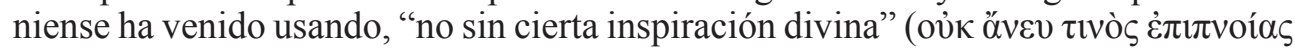
$\theta \varepsilon \tilde{\omega} v), \mathrm{y}$ “enunciado en una forma sumamente parecida a la de una poesía” (811c) ${ }^{21}$.

\footnotetext{
Colli (2008: p. 168); Mouze (2005: pp. 149-152).

Lledó (2010: p. 115), y Steiner (2012: p. 60).

21 Mouze se refiere en términos parecidos a este proceso, señalando que poesía y ley comparten su inmutabilidad (2005: pp. 280s.) y su esencia inspirada y divina (2005: p. 284). Destaca también el carácter dialéctico del mismo, pero entiende su culminación como una especie de equilibrio entre ambas que preserva la naturaleza de poeta y poesía. Conclusión que encuentro difícilmente compatible con su reconocimiento de que el legislador es el poeta por excelencia, y de que su finalidad es desposeer a éste de su palabra (2005: pp. 303s., 323).
} 
En realidad, si se analiza en perspectiva, este proceso podría interpretarse como la consumación a la inversa del emprendido por Gorgias en su Encomio de Hele$n a^{22}$ : el lógos platónico absorbe la potencia del lenguaje poético, al que restituye su naturaleza, no ya sacra, sino cultual, por medio de la preceptiva de $800 \mathrm{e}-801 \mathrm{~b}$, en un desesperado intento por revertir la ineludible marcha de los dioses del mundo humano ${ }^{23}$. Aunque el golpe maestro lo asesta Platón al trasladar a la ley la sustancia de lo poético:

Nosotros mismos somos autores en lo que cabe de la más bella y también de la más noble tragedia; pues todo nuestro sistema político consiste en una representación de la más hermosa y excelente vida, que es lo que decimos nosotros que es en realidad la más verdadera tragedia. Poetas, pues, sois vosotros, pero también nosotros somos autores de lo mismo y competidores y antagonistas vuestros en el más bello drama que el único que por naturaleza puede representar... es la ley (817b).

Ya no son, como en la República, los individuos concretos quienes construyen con sus acciones un terreno de encuentro entre la realidad y el deseo, y dan "forma a lo bello en la vida humana", como también quisieron muchos románticos ${ }^{24}$; sino la ley: la única instancia capaz, en efecto, de sintetizar vida y pensamiento, de borrar la contingencia ${ }^{25}$, materializando "el bien y la hermosura superior al placer" (663a). Placer que, no obstante, se integra en un vínculo con la justicia que resulta de lo "más útil y eficaz para llevar a todos a obrar en todo con justicia, no ya por fuerza, sino por voluntad" (663d-e). Entre estos productivos placeres se encuentran la poesía, con la que "uno puede persuadir las almas de los jóvenes de aquello que se proponga" (663e-664a), y conseguir que gocen de lo superior tanto como en la actualidad se goza de lo inferior (802c-d); y el vino, ese phármakon milagroso que permite "conocer la naturaleza y los hábitos de las almas" (650b), y que Dioniso dio a los hombres para "olvido de la pesadumbre" (666b), y "para que adquiriésemos el pudor del alma y la salud y la fuerza del cuerpo" (672d) ${ }^{26}$.

Sin embargo, los placeres primarios siguen siendo enfermedades (voбń $\mu \alpha \tau \alpha)$, males por los que "siente todo ser vivo un congénito amor ( consideración que afecta especialmente al deseo sexual, por ser éste el más inten-

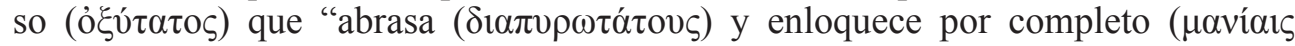

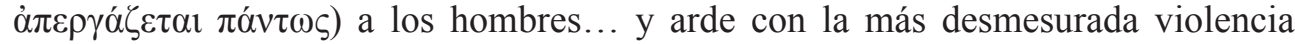

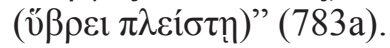

22 Macua (2014: pp. 126s., 134-137).

23 Desde este punto de vista, tal vez podría resolverse la contienda entre Bobonich (2004: pp. 104-106 y 109-116) y Mouze (2005: pp. 166-168) sobre el tipo de persuasión que pretenden los preludios a las leyes: la visión gorgiana del lenguaje como téchne que, manejada con precisión por la razón humana, permite obtener los mismos efectos fascinadores que los poetas se han arrogado en exclusiva y atribuido a la inspiración divina, comparte con éstos la comprensión de la psicología de la comunicación verbal como un proceso mágico (goeteía, Helena, 10) que hechiza (éthelxe, Helena, 10) y "marca” (etypósato, Helena, 13) el alma del oyente, haciéndole visible (phainesthai, Helena, 13) lo ininteligible. El lógos de la ley platónica recupera el origen divino del que Gorgias lo había emancipado; y, siendo expresión de la razón en su forma más elevada (la razón de la divinidad: Bobonich 2004: p. 9), no sólo es "inspirado" por derecho propio, sino también porque, con la conversión de la poesía en culto y ley, es capaz, ahora sí, de integrar sin riesgos toda la potencia fascinadora y persuasiva de aquélla.

24 Todorov (2007: pp. 232s.); Safranski (2013: p. 131).

25 Safranski (2013: p. 89).

26 Frente a la condena de la embriaguez en $R$. 398e y $403 \mathrm{e}$. 
La intensidad es también el rasgo que define "la naturaleza de la amistad y de

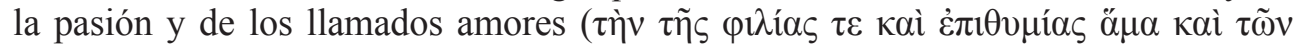

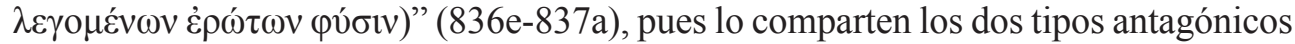
de relación erótica: la que procede de los contrarios y la que procede de los semejantes, a las que indistintamente llamamos ě $\rho \omega \tau \alpha$ "cuando una y otra amistad adquieren vehemencia ( $\sigma \varphi \circ \delta \rho o ́ v) "$ (837a). La primera "es arrebatada y selvática y raras veces mantiene entre nosotros la reciprocidad; la que procede de los semejantes es mansa y también recíproca de por vida" (837b). Hay, además, un tercer tipo de amor, "que nace de la mezcla de ambas" y que es "difícil de comprender" (837b). En cualquier caso, la diferencia fundamental entre ellas radica en el móvil del amante: uno,

enamorado del cuerpo y hambriento de la flor como si fuera el fruto, se exhorta a sí mismo a saciarse de ella, sin otorgar el menor aprecio al carácter del alma del amado; el otro, en cambio, dando de lado como accesorio al deseo del cuerpo, mirando más bien que amando, apasionado realmente del alma con el alma, tiene por desafuero la posesión del cuerpo, y venerando y respetando al mismo tiempo la moderación, el valor, la generosidad y la prudencia, quisiera conservar perpetuamente su castidad con la castidad del amado (837c-d).

El objeto de este segundo tipo de amor es, como en los diálogos de antaño, "la virtud, pues tiende a que el joven se haga lo mejor posible" (837d). Pero la virtud de las Leyes bascula, como decíamos, sobre el aidós, no sobre el thymós: no es motor interno del movimiento ascensional del alma, sino un sentimiento que se proyecta hacia afuera y somete el alma al control público externo que representa la ley ${ }^{27}$; disuelve, no elabora, la sustancia del éros: esa intensidad característica del deseo sexual con la que los intelectuales del siglo V contaminaron al éros "genérico", que Platón recondujo en el pasado como anhelo de trascendencia, pero a la que ahora

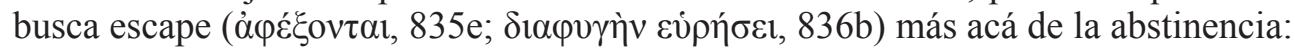
en la menos ardua y dócil "cohabitación reproductora, absteniéndose de la unión con varón... absteniéndose igualmente de todo surco femenino en que no se quiera que brote lo sembrado" (838e-839a).

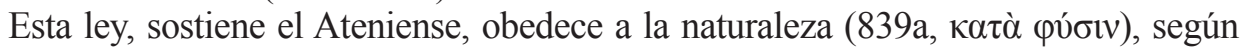
prueban los hábitos sexuales de muchos animales (840d); y "no está vi $\pi \dot{\varepsilon} \rho$ öv $\theta \rho \omega \pi 0 v$ " (839d), tal como demuestra la disciplina de los atletas (839e-840b), cuya compensación es, sin embargo, muy inferior a "la felicidad que aporta la mejor victoria" (sobre los placeres) (840b-c). La dificultad para ponerla en práctica deriva, nos dice, de la incredu-

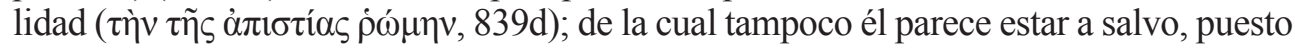
que toma la precaución de dar una segunda ley, por si, a pesar de la primera, persistiera "el desorden de Afrodita" (840e) entre "los estragados en sus naturalezas, que llamamos vencidos por sí mismos" (841b): éstos deberán, al menos, ocultarse de la vista de los demás, so pena de "exclusión de la totalidad de los honores ciudadanos" (841e).

En cierto sentido, podríamos hablar de un retorno a la concepción socrática del éros como educación perenne para vencer los instintos más bajos, con el fin de alcanzar la serenidad apolínea donde la vida en común no tiene contradicciones y la pasión queda eliminada ${ }^{28}$ : como en los sosegados jardines de Íbico (286 PMG) y de

\footnotetext{
Mouze (2005: pp. 102 y 261).

28 Colli (2011: p.137).
} 
Safo (fr. 2 LP); o, tal vez, como en el ánimo encogido del Lisias del Fedro y de la nodriza del Hipólito, para quienes "la estimación que los mortales se profesan habría de ser moderada y no llegar a lo más íntimo del alma" (Hipp. 253-57).

Se trata, en mi opinión, de un proceso de involución paralelo al que experimenta la poesía, y que viene acompañado por un uso de la terminología erótica mucho más parecido en las Leyes al de Homero o Eurípides ${ }^{29}$, que al del propio Platón del Banquete o la República: en efecto, frente a la cuidada elaboración del éros genérico y de sus objetos, y la definición de fronteras con el éros específico que caracteriza a estos diálogos ${ }^{30}$, encontramos en las Leyes una especie de borrado de la línea de demarcación entre ambos, y un lenguaje erótico que, como el de esos poetas, incluye también usos banales ${ }^{31}$.

El deseo humano no se debate ya entre lo mundano y lo transmundano: oscila

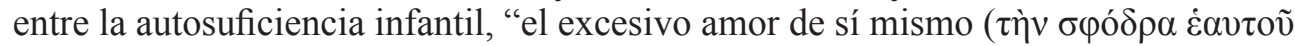

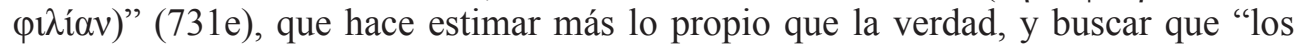
sucesos todos... se acomoden al orden impuesto por su alma" (687c), en lugar de intentar "que esa voluntad ( $\beta$ ov́ $\lambda \varepsilon \sigma ı v$ ) se acomode aún en mayor grado a la propia ra-

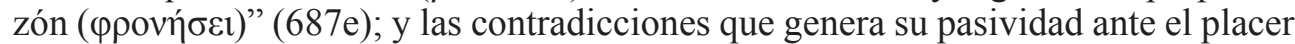
y el dolor (644c), que "a manera de unas cuerdas o hilos interiores, tiran de nosotros y nos arrastran..." (644e), y nos hacen "pública o privadamente enemigos de todos los demás, y cada uno también enemigo de sí mismo" (626d) ${ }^{32}$.

En las Leyes, el hombre "no es más que un juguete inventado por la divinidad" (803c), un títere cuyos hilos ha de manejar el legislador, para que "pasen su vida jugando a los juegos más hermosos", en lugar de imaginar "que es justo que las ocupaciones serias sirvan únicamente con miras al juego" (803c-d). En este universo infantil, empequeñecido, el individuo parece condenado a topar siempre con la contingencia de lo privado y su eterno roce con el más alto bien común (875a-c); lo mismo que el legislador, que de mala gana le concede un reducto (739b-e), y asume la mezquina tarea de regularlo,

porque, aunque a causa de su insignificancia... sería improcedente y al mismo tiempo feo el dictar leyes... estas cosas son capaces, por otra parte, de dañar incluso a las leyes escritas y vigentes, porque en lo menudo y cotidiano se acostumbran los hombres a transgredir. De manera que no sabe uno cómo legislar acerca de ello, pero también es imposible callarse (788b-c).

Por otra parte, no queda en este diálogo rastro de aquel "lugar supraceleste" que alcanzaba el buen amante en el Fedro y el Banquete, y que esperaba en la República tras la muerte a las almas nobles. No hay promesa de más allá en las Leyes: sólo la

\footnotetext{
Ludwig (2002: pp. 127-136).

Macua (2016: pp. 151-165).

31 Sirva de ejemplo el pasaje del libro VIII dedicado a la regulación de la caza: “Amigos, ojalá que jamás os coja

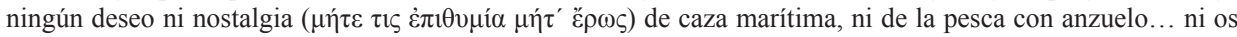

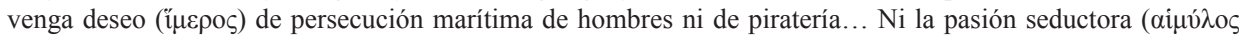
है $\omega \varsigma)$ de la caza de aves... (823-e).

32 Tampoco en este aspecto difiere demasiado la visión que tiene Platón en las Leyes del éros "errado", de la que expone Han cuando describe al actual sujeto narcisista, que contempla el mundo como proyección de sí mismo (2014: p. 11; y 2016: p. 49), y al otro como "objeto de consumo y de cálculo hedonista" (2014: p. 34): "La especie humana libra una guerra consigo misma ... Las guerras no se libran solo contra el otro, sino fundamentalmente contra uno mismo" (2016: p. 186).
} 
vinculación del interés personal al todo armónico del que somos porción, y al que

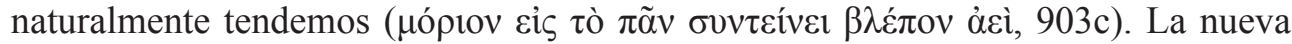
pólis de Platón es un reino de este mundo, donde los hombres buenos son ya, necesariamente, felices (742e), y los que no aspiran al bien, sufren el peor de los castigos: "hacerse semejante a los hombres que son malos y, una vez asimilado a ellos, el huir de los hombres buenos... y perseguir a sus contrarios adhiriéndoseles en el trato social" (728b); amén de la pena de muerte para aquéllos que resulten "incurables", con la que podrán, por fin, "beneficiar doblemente a los demás, por servirles de escarmiento ... y por dejar la ciudad libre de malvados" (862e).

La intensidad del deseo, sea cual sea su objeto, no implica ahora más que riesgos. Lo mismo que el impulso que la alimenta: el thymós, la virtud que hacía el alma de los guardianes "intrépida e indomable” en la República (375b), y que ha pasado a ser

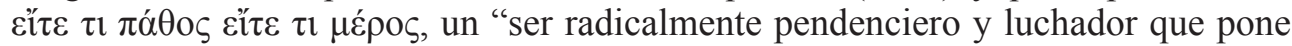
en ruina muchas cosas con violencia irracional"; una fuerza que opera con un mecanismo doloroso (la envidia), pero que, como el placer, "impone... cuanto le viene en gana" $(863 b)^{33}$.

Junto con ellos, ahuyenta Platón la sombra de la antigua pederastia, un "desafue-

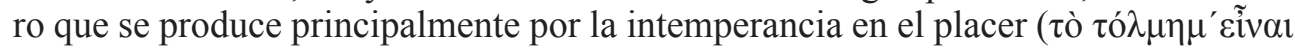

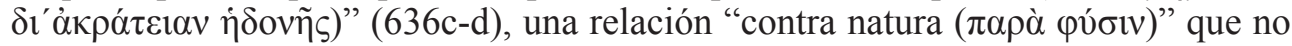
contribuye a enraizar "en el alma del seducido... el hábito del valor, o en la del seductor el carácter de la templanza ... Y en cuanto al que toma el papel de mujer, ¿quién no lamentará la semejanza con su modelo?” (836d-e) ${ }^{34}$.

Porque, aunque en un primer momento aparece como prioridad del legislador la naturaleza de las relaciones eróticas, no su objeto específico, de manera que se aprueban las que conducen a la virtud de amante y amado, mientras se prohíben las otras; esta condena repetida de la pederastia (636b-d y 836c-e) pone al descubierto un interés diferente y superior, a cuyo servicio está el proceso de "domesticación" del éros, paralelo al que experimenta la poesía, y por el que pierde, igualmente, su vinculación con lo divino, su potencia ascensional, quedando constreñido dentro del corsé de la naturaleza como instinto de procreación (784e), única vía de inmortalidad que esta obra reconoce,

considerando que el género humano participa de algún modo, y por carácter natural, de la inmortalidad, y que en todo él es innata el ansia de alcanzarla en todos sus respectos. El hacerse famoso y no yacer en el sepulcro sin dejar nombre constituye un deseo de inmortalidad. El linaje de los hombres es de cierto algo vinculado por naturaleza con la totalidad del tiempo, que le sigue y le seguirá perpetuamente; éste es su modo de ser inmortal: dejando hijos de sus hijos, siendo siempre uno y el mismo, participar de la inmortalidad por la generación ( $\gamma \varepsilon v \varepsilon ́ \sigma \varepsilon l)(721 \mathrm{~b}-\mathrm{c})$.

33 El thymós queda así definitivamente vinculado a la envidia, excluyéndose su potencial manifestación como philía, como conciencia de grupo que genera solidaridad y acción común, y empuja al combate contra la injusticia (Ludwig 2002: pp. 192-198; Macua 2016: pp. 161-163). Sobre la visión negativa del mismo y su pérdida de papel con respecto a la República, véase también Bobonich (2004: pp. 26-28). En cambio, para Renaut (2013: pp. 105 y 108-110), su función es básicamente la misma que en República: como sede del aidós, y disociado de su objeto tradicional (la timé), actúa como guardián del deseo sexual y colabora con la razón.

34 Platón despoja en esta obra al éros pederástico de su halo de aristocrática masculinidad, destacando, por el contrario, su vinculación con la hýbris, característica de la mentalidad democrática ateniense (Ludwig 2002: pp. 50-54, 171-179). 
El ansia de inmortalidad que Sócrates señalaba en el Banquete como genuino objeto de éros, y para la que abría cauces mejores que el de la procreación, se satisface en las Leyes dentro de los exclusivos, naturales y mundanos límites de ésta, en los que pueden convivir sin estridencias el interés particular y el común, el objeto del éros específico y el del éros genérico.

Así son, por fin, domesticados, éros y poesía, a costa de perder su naturaleza divina y su capacidad para mediar en un diálogo ya inviable entre dioses y hombres (Symp. 202e-203a). Al mismo tiempo, su concepción experimenta un proceso de involución por el que la poesía retorna a su origen cultual y recupera su papel pedagógico, aunque su potencial "encantador" y creativo queda finalmente disuelto en el lógos persuasivo y coercitivo de la ley, el único en el que se manifiesta la divinidad, y por el que concede a esas marionetas que ahora son los hombres unas normas inalterables que tiran de "el hilo de oro de la razón, precioso pero frágil" 35 , dirigiendo "la representación de la vida mejor y más noble" en el gran guiñol del mundo. Un lógos que ha logrado liberarse de la finitud de sus usuarios, pero dejando en el camino su aliento vital (Phdr. 276a).

De igual modo, el éros diluye su vehemencia y sus contradicciones en el natural instinto de procreación que pretende colmar a un tiempo deseo sexual y anhelo de trascendencia, desdibujados ambos, en su especificidad y en sus intersecciones, por un uso indiscriminado, muchas veces banal, de la terminología erótica; y gobernados por un aidós que contiene al hombre en los límites que le son propios, y en los que tampoco cabe ya la dialéctica, fruto de ese mismo anhelo intenso e insaciable que castra la Ley a cambio de sacarnos de otra caverna: la de la nuestra propia interioridad.

Éste fue el último intento de Platón de materializar y consolidar esos espacios donde los poetas habían ubicado un alivio siempre efímero al dolor y al mal. Tal vez habría que interpretar su afirmación de que el mal no puede borrarse, "ya que ha de ser siempre algo opuesto y contrario al bien; tampoco puede hallarse entre los dioses, sino que necesariamente tiene que merodear por la tierra y en torno a nuestra naturaleza mortal" (Teeteto, 176a); y su aceptación del abismo insalvable que media entre la divinidad y el hombre, como concesiones finales al saber de los poetas. Pero jamás renunció Platón a la posibilidad de "salvación", que ha de ser siempre, necesariamente, colectiva, y para la que creó en las Leyes un último espacio compartido donde aún "puede mostrase lo sagrado" en un culto y una ley inalterables que sintetizan "lo que poetiza y lo que vive" ${ }^{36}$, recreando una completud ${ }^{37}$ que congela la frágil presencia de los dioses en el mundo y el débil vínculo entre el yo falsamente autosuficiente y los otros: "La felicidad de la metafísica antigua no es solitaria. El mundo verdadero es en esta metafísica una realidad social"38. Una casa común.

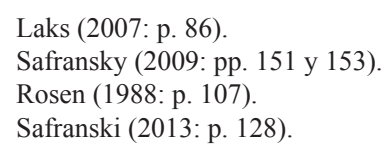




\section{Bibliografía}

Andrés Ruiz, E. (2017), La carroña. Ensayo sobre lo que se pierde, Valencia.

Bloom, H. (1999), La Compañía visionaria. William Balke, Buenos Aires.

Bobonich, Ch. (2004), Plato's Utopia Recast. His Later Ethics and Politics, Oxford.

Boehringer, S. (2007), “Comment classer les comportements érotiques? Platon, le sexe et erôs dans le Banquet et les Lois", Études platoniciennes IV: 45-67.

Bruchmüller, U. (2009), "La posibilidad del Estado ideal de Platón en la República y en las Leyes. Una alternativa a la interpretación de André Laks de la filosofía política de Platón”, Dianoia LIV, 63: 175-195.

Colli, G. (2008), Platón político, Madrid.

Colli, G. (2011), Filósofos sobrehumanos, Madrid.

Grassi, E. (2016), Arte como antiarte. Ensayo sobre la teoría de lo bello en el mundo antiguo, Barcelona (Köln, 1962).

Han, B.-Ch. (2014), La agonía del Eros, Barcelona.

Han, B.-Ch. (2016), Topología de la violencia, Barcelona.

Laks, A. (2007): La filosofía política de Platón a la luz de las Leyes, Mérida.

Lledó, E. (2010), El concepto de poíesis en la filosofía griega. Heráclito, sofistas, Platón, Madrid.

Ludwig, P. W. (2002), Eros and Polis. Desire and Community in Greek Political Theory, Cambridge.

Macua, M.E. (2014), “Una interpretación alternativa de la crítica platónica a la poesía: las soluciones de Platón a la crisis poética del siglo V", $C F C(G), 24:$ 123-144.

Macua, M.E. (2016), “Éros y poesía en Fedro, Banquete y República: la reelaboración platónica de los terrenos poéticos para la realidad y el deseo", $C F C(G), 26: 145-167$.

Mouze, L. (2005), Le législateur et le poète. Une interprétation des Lois de Platon, Lille.

Renaut, O. (2013), "Challenging Platonic Erôs: The Role of Thumos and Philotimia in Love", en E. Sanders-Ch. Thumiger-Ch. Carey-N. J. Lowe (eds.), Erôs in Ancient Greece, Oxford: 95-110.

Rosen, S. (1988), The Quarrel between Philosophy and Poetry, New York.

Safranski, R. (2009), Romanticismo. Una odisea del espíritu alemán, Barcelona.

Safranski, R. (2013), ¿Cuánta verdad necesita el hombre?, Barcelona.

Steiner, G. (2011), La poesía del pensamiento. Del helenismo a Celan, Madrid.

Todorov, T. (2007), Los aventureros del absoluto, Barcelona.

Walsh, George B. (1984), The Varieties of Enchantment. Early Greek Views of the Nature and Function of Poetry, Chapel Hill and London. 